\title{
Instructional Model for Social Skills Intervention Children with Visual Impairment
}

\author{
Norshidah Mohamad Salleh', Khalim Zainal² \\ ${ }^{1}$ Department of Education and Community Wellbeing, Universiti Kebangsaan Malaysia, Bangi, Malaysia \\ ${ }^{2}$ Pusat CITRA, Universiti Kebangsaan Malaysia, Bangi, Malaysia \\ Email:nshidah@ukm.edu.my, kz@ukm.edu.my
}

How to cite this paper: Salleh, N. M., \& Zainal, K. (2018). Instructional Model for Social Skills Intervention Children with Visual Impairment. Creative Education, 9, 2325-2333.

https://doi.org/10.4236/ce.2018.914172

Received: August 16, 2018

Accepted: October 27, 2018

Published: October 30, 2018

Copyright (c) 2018 by authors and Scientific Research Publishing Inc. This work is licensed under the Creative Commons Attribution International License (CC BY 4.0).

http://creativecommons.org/licenses/by/4.0/

(c) (i) Open Access

\begin{abstract}
This paper discusses a proposed instruction model for intervention of social skills children with visual impairment. Intervention model based on Badura's Social Cognitive Learning Theory were proposed to help students with visual impairment in the development of their social skills. The emphasis of the theory was based on imitation, environment and cognition. The three elements are interrelated in the development of social skills and individual behavior. The theory stressed the process of learning behavior through imitation. Without visual information, the imitation was learnt from the information through hearing and touch as well as physical model. The process of imitation was received with reward, reinforcement and motivation will strengthen the social skills learned and the target behavior. In addition, teachers, parents and the communities have an important role in helping and training the visually impaired children to improve their social skills. The impact of the proposed intervention model, the social skill of visual impairment children will be improved so that they can be socialized effectively with typical children.
\end{abstract}

\section{Keywords}

Visual Impairment, Social Skills, Imitation, Bandura's Social Cognitive Theory, Intervention Model

\section{Introduction}

The inability to see is a major impediment to children with visual impairment (CVI) to get visual information about the environment. This is a very critical constraint to the learning process because the information received from other senses; through hearing, touch and taste can't provide overall picture and information over information through vision (Ferrell, 2006; Hill \& Blasch, 2010). The 
lack of information received not only affects the aspects of learning, but also the development of social skills and their behaviors (Ferrell, 2006; Celeste, 2007; Friend, 2005; Sacks \& Wolffe, 2006).

Studies show that CVI are also more likely to be immature and egocentric social skills than typical children. This is due to the lack of opportunities for socializing as well as the inability to observe and imitate the behavior of peers around them (Tuttle \& Tuttle, 2004; Jessup, Bundy, Broom, \& Hancock, 2017). They are more likely to social exclusion or have a feeling of being alone and lonely because they are not able to have friends to communicate. They had to wait for others to start a conversation. Isolation is also due to uncertain of other typical individuals how to interact well when meeting individuals with visual impairment. The difficulty in overcoming the social isolation experienced by individuals with visual impairments causes them to easily give up and withdraw (Tuttle \& Tuttle, 2004). CVI are also seen to be passive and not aggressive (Celeste, 2006; MacCuspie, 1996).

CVI are prevented to learn the correct situation or behaviors, and it will make them behave wrongly (Celeste, 2007; Celeste, 2006; MacCuspie, 1996; MacCuspie, 2001). This situation is very difficult for them and mostly they stick to the motto "it's better not to do something than to make something wrong". Withdrawal is better than doing something that can embarrass themselves (Tuttle \& Tuttle, 2004). In addition, CVI are also difficult to imitate the model or appropriate example due to the inability to learn social behavior around them. Their opportunity to participate in social situations is limited because various observations are very limited or did not happen (Bandura, 1977; Bandura, 1986). This condition causes CVI have little basis to make comparisons and they did not realize that some of their social behaviors are not accepted. For example, blindism (self-stimulating behavior) is a social behavior that is not accepted by typical people but often performed by blind people. This is because they are not aware that behavior is not performed by others. This will pose misconceptions against blind individuals and their characteristics as appropriate and acceptable by other people (Tuttle \& Tuttle, 2004; Lieberman, Haegele, Columna, \& Conroy, 2014; Salleh \& Zainal, 2010).

\section{Curriculum for Student with Visual Impairment}

In Malaysia's education system, student with visual impairment follow The National Curriculum same as other children. They are capable of following the mainstream curriculum because they are only limited in terms of visual perception due to visual impairment. The cognitive development and learning ability, CVI are seen to have the same cognitive abilities as well as other children.

The Malaysian Ministry of Education has introduced a transformation curriculum through the Primary School Standard Curriculum (KSSR) and the Secondary School Standard Curriculum (KSSM). The curriculum is being implemented in year 2011 stages by stages, beginning with year one in the primary school (Malaysian Ministry of Education, 2012; Malaysian Ministry of Educa- 
tion, 2011). In the implementation of KSSR, two new subjects; Information and Communication Technology (TMK) and Basic Skills for Visually Impaired Individual (KAIMaL) are introduced for students with visual impairment. The subjects aimed at providing exposure to visual impaired students with knowledge, skills and values to master the skills in daily life. KAIMaL contains orientation and mobility training modules, brailling skills and knowledge on special equipment. Both TMK and KAIMaL subjects are taught formally after being developed in KSSR. The subjects contain the basic skills that must be learned by SVI to help them master other subjects with communication-assisted skills so that they can live independent without relying on other people.

Special Education KSSR for CVI does not offer related learning social skills such as curriculum for students with learning disabilities. They are not formally taught about the necessary social skills because of the absence of additional curriculum or intervention modules in the school. They are expected to master social skills as other students. However, many studies show that the performance of social skills among visual impairment students is lower compared to typical students (Hatlen, 2004; Ruijs, Peetsma, \& Van Der Veen, 2010; Salleh, Ali, \& Zainal, 2017). According to Sacks \& Wolffe, 2006, lack of vision or limited vision ability, an understanding of non-verbal language is a significant constraint for CVI to communicate. Without an understanding of basic social skills such as social signal ability, CVI are difficult to interact with their peers because children always provide social signals during play time and this situation does not occur among blind children (Celeste, 2006). The inability to see, their behavior will be restricted in social interactions such as no turn-taking skills during play, inability to invite friends to play together and they unable to keep friendship with peers. As a result they are often ignored by playmates and other children (Jessup, Bundy, Broom, \& Hancock, 2017; Lieberman, Haegele, Columna, \& Conroy, 2014; Sacks \& Silberman, 2000).

According to Bowen (2010a), high self-esteem has a correlation with social skills. CVI who are able to translate the social behavior of others, understand social conditions and well behave have the advantage in forming self-esteem. However, experience related to such skills does not apply naturally. Instead they need to be taught and train with structured and systematic to acquire the necessary social skills experience especially for children with low self-esteem. The study by Bowen (2010b), shows that interventions can increase the self-esteem of visually impaired students. Therefore action needs to be taken to assist CVI to learn the social skills that need to be aligned with the learning of academic subjects. Early intervention implementation can help them master the necessary social skills (Corn \& Erin, 2010; Visagie, Loxton, Stallard, \& Silverman, 2017). The deficit of social skills can be taught and trained so that they can adapt themselves to the groups and communities.

\section{Theorical Frame}

One of the theories that explain the development of social skills among children 
and their relationship to the formation of children's behavior is Social Cognitive Learning Theory. The theory founded by Bandura was chosen as the basis of the discussion of framework in understanding the process of socialization and social behavior of children, especially children with visual impairments.

The Social Learning Theory introduced by Albert Bandura (Bandura, 1977), explains that learning process is the result of one's observation of the surrounding behavior. The individuals observed the models behaviors and then imitated the behaviors. Bandura found an important element, cognition is needed during the observation process through modeling (Boyd \& Bee, 2014; Eggen \& Kauchak, 2015; McDevitt \& Ormrod, 2016; Santrock, 2015). The three main elements emphasized in Bandura's Social Cognitive Learning Theory are behavior, mental activity (cognition) and environment. These three elements influence the learning process and the formation of individual social cognitions and are interconnected. Bandura believes that individual behavior is the result of internal interaction (cognition) with the environment. The child will observe the behavior in his environment based on the model, followed by mental activity such as memorizing and store the behavior he sees and so will demonstrate the behavior in the appropriate situation. The resulting of behavior may apply immediately or vice versa. If the behavior is motivated, the imitation of the behavior will be repeated (Kail, 2015).

According to social cognitive learning theory, cognitive processes will affect individual behavior if reward and punishment can be generated to produce something meaningful (Eggen \& Kauchak, 2015). For CVI who experience a vision problem, the reward can only change behavior if they know the resulting of behavior that will be reward. This approach is used in implementing intervention and teaching programs related to social skills for CVI. The teacher needs to be clear with the behavior to be reinforced so that the students can adapt themselves to a reasonable behavior. Teachers also need to provide clear feedback to ensure the students know the behavior they are getting reinforced (Zainal, 2014).

Modeling is a channel for learning abstract information as well as learning about concrete skills (Bandura, 1986; Bandura, 2001). Imitation of models is the basic concept of Social Cognitive Learning Theory where behavior, cognitive and effective change as a result of individual observations of one or more models. The imitation process involves some forms of imitation including direct imitation, symbolic and synthesis imitation (Eggen \& Kauchak, 2015). Direct imitation occurs when the children imitate directly the observed behaviors model. Teachers play a role of providing imitative experience to CVI through demonstration of physical imitation as an alternative to imitation model of vision. While through symbolic imitation, children will imitate the behavior described in books, games, movies or television. Children who experience visual impairment can learn abstracts through symbolic imitation even without visibility as they are able to listen, read, remember, and absorb the behavior of the illustrated models.

Synthesized imitation demonstrates the ability of children to behave by com- 
bining several parts of the observed behavior. A series of observations and learning of the model will be stored and then combined to produce more meaningful behavior according to the situation. Synthesized imitation will result cognitive imitation because synthesis learning involves the storage of information that is individual cognition. According to Schunk (2012), teachers can teach more effectively using cognitive imitation which is a process that combines the verbal and the thought of the behaviors shown. CVI can be trained to understand the behavior through organized learning, additional time and diverse approaches in learning cognitive imitation. Through a variety forms of imitation, either directly, abstract, synthesized, and cognitive, CVI can improve their attitudes, values, problem solving and self-assessment about their social behavior (Boyd \& Bee, 2014; McDevitt \& Ormrod, 2016; Santrock, 2015).

\section{Proposed Teaching Model for Social Skills Intervention}

The Bandura Social Cognitive Learning Theory, which involves imitation processes for the learning of social behavior; observational, storage, outcome and motivation (Bandura, 1986; Bandura, 2007) has been applied extensively as a method to train CVI (Sacks \& Wolffe, 2006). Here's a propose teaching model for the intervention social skills of CVI. This model emphasizes the learning process involves imitation model of environment information and cognition process. Physical modeling, verbally feedback, realistic rewards and consistent instruction can reinforce the learning behavior. Applications to the concept of social cognitive learning through a well-organized and comprehensive intervention program as well as diverse learning strategies, CVI can be trained to improve their social skills (Celeste, 2007; Celeste, 2006). Training should be carried out according to the needs and levels of child development, stage-by-stage and ongoing. Besides motivating either directly or indirectly, various forms of reinforcement need to be addressed during the intervention. The proposed intervention model is formulated as the diagram (Figure 1).

Interventions to be conducted should be organized in advance of the aspects of social skills that need to be taught, the timeframe for achieving the objectives and the targets. Social skills proposed for the teaching students with visual impairment consisting of non-verbal communication skills, conversation initiation skills, skills to engage in social activities, skills to discuss the visual impairment experienced with others, self-appearance skills, and skills in maintaining relationships with peers.

Some approaches can be used by teachers to conduct interventions such as modeling, mentoring, role playing and peer intervention. Teachers can choose the appropriate approach and strategy. Sacks \& Wolffe (2006) suggests possible strategies that teachers can apply in implementing interventions based on proposed model proposals; involving peers in intervention programs, providing appropriate settings for intervention, setting the duration and frequency of interventions, applying social skills teaching in real situations and evaluating teaching 


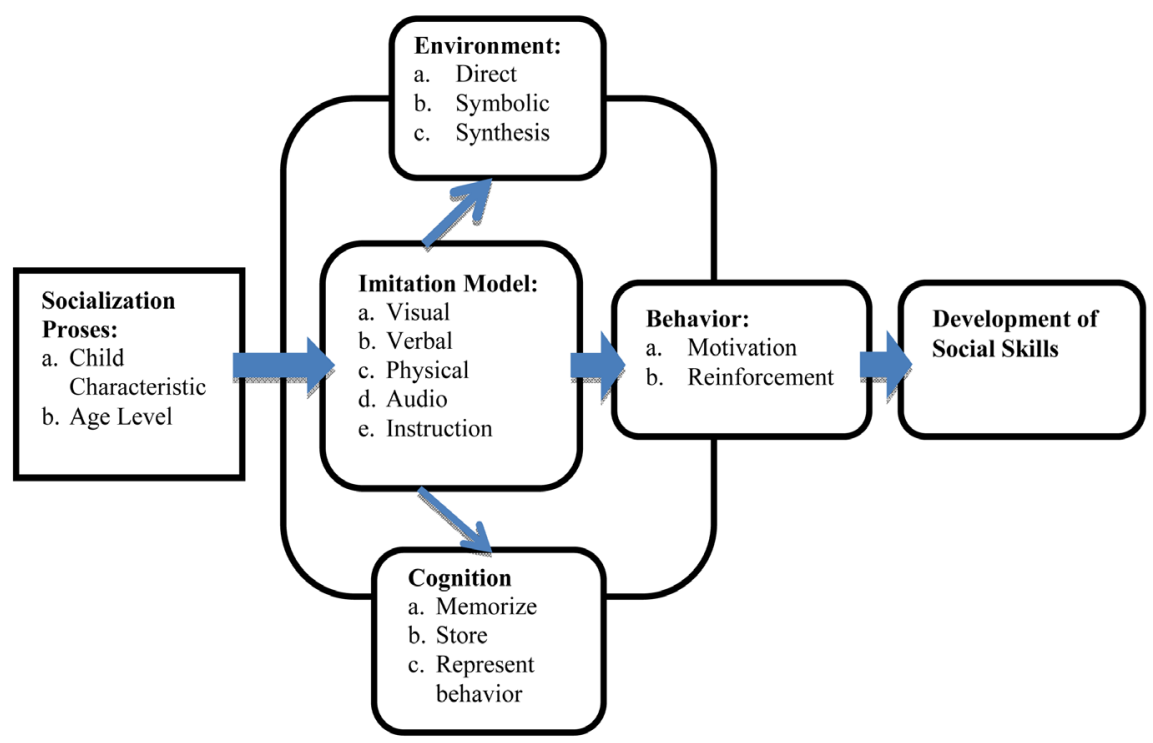

Figure 1. Teaching models of intervention social skills for students with visual impairment based on bandura's social cognitive learning theory.

outcomes. Evaluations can be carried out in stages to determine the effectiveness of interventions.

\section{Summaries and Implication of the Study}

Without visual input, the acquisition of social skills does not occur naturally among CVI. They require formal learning of social skills through training and intervention throughout the school period. Implementation of early intervention can train CVI to master social skills as early as possible (Salleh, Ali, \& Zainal, 2017). Teachers have a very important role in implementing interventions and managing student's behavior (Zainal \& Salleh, 2012). They need to be trained with the knowledge and skills to teach students with the necessary social skills and know how to conduct an assessment. Additionally, teachers need to emphasize on the social skills of students who are weak and reinforce the social skills that the students have mastered during the intervention program. The strength of student-dominated social skills can also be used to reinforce the weak aspects of social skills.

Besides teachers, parents and families also have a great influence on the education and behavior of children (Amin, Manap, \& Md Akhir, 2016). Before schooling time, parents and other family members are model and mentors to children. Children's attitudes and behavior are reflecting by the discipline received from their parents. Parents play an important role in educating and training their children at home with the necessary social skills and social behaviors received by members of the community. In addition, parents should treat their CVI as a child and not as an individual with visual impairments. CVI also needs love, acceptance and appreciation from their parents. Parent's attitude of suspicion and overprotection, will cause the child to have difficulty living in daily 
life (Sacks \& Wolffe, 2006; Holbrook, 2006; Sacks, Kekelis, \& Gaylord-Ross, 2001).

Parents need to encourage their CVI to do something on their own alone without relying on others. Parents should also act wisely when their child makes a mistake and needs to be strict about their child's behavior and appearance. They are as a mirror to CVI. Parents' ability and willingness to train their children to master social skills can help their children achieve social development and well-being and become respected human beings. Support from all parties, especially the school and the parents, is needed in order to enhance the social skills of CVI. The mastery of high social skills can give them confidence to interact with the community and able to live independently together with other children.

\section{Conflicts of Interest}

The authors declare no conflicts of interest regarding the publication of this paper.

\section{References}

Amin, A. S., Manap J., \& Akhir, N. Md. (2016). The Role of Family in the Lives of Disabled Malaysian Children, Akademika, 86, 21-30.

Bandura, A. (1977). Social Learning Theory. New York: General Learning Press.

Bandura, A. (1986). Social Foundations of Thought and Action: A Social Cognitive Theory. Upper Saddle River, NJ: Prentice Hall.

Bandura, A. (2001). Social Cognitive Theory: An Agentic Perspective. Annual Review of Psychology, 52, 1-26. https://doi.org/10.1146/annurev.psych.52.1.1

Bandura, A. (2007). Social Cognitive Theory. In W. Donsbach (Ed.), International Encyclopedia of Communication. Thousand Oaks, CA: Sage. https://doi.org/10.4135/9781412952651.n280

Bowen, J. (2010a). Visual Impairment and Its Impact on Self-Esteem. The British Journal of Visual Impairment, 28, 47-56. https://doi.org/10.1177/0264619609349429

Bowen, J. (2010b). Visual Impairment and Self-Esteem: What Makes a Difference? The British Journal of Visual Impairment, 28, 235-243. https://doi.org/10.1177/0264619610375504

Boyd, D., \& Bee, H. (2014). Lifespan Development (7th ed.). New York, NY: Pearson International.

Celeste, M. (2006). Play Behaviors and Social Interactions of a Child Who Is Blind: In Theory and Practice. Journal of Visual Impairment \& Blindness, 100, 75-90.

Celeste, M. (2007). Social Skills Intervention for a Child Who Is Blind. Journal of Visual Impairment \& Blindness, 101, 521-533.

Corn, A. L., \& Erin, J. N. (2010). Foundation of Low Vision: Clinical and Functional Perspective (2nd ed.). New York, NY: AFB Press American Foundation for the Blind.

Eggen, P., \& Kauchak, D. (2015). Educational Psychology: Windows on Classrooms (10th ed.). New Jersey: Pearson Education Inc.

Ferrell, K. A. (2006). Your Child's Development. In M. C. Holbrook (Ed.), Children with Visual Impairment: A Parents' Guide (2nd ed., pp. 73-96). Bethesda, MD: Woodbine House. 
Friend, M. (2005). Special Education: Contemporary Perspectives for School Professionals. New York: Pearson Education Inc.

Hatlen, P. H. (2004). Is Social Isolation a Predictable Outcome of Inclusive Education? Journal of Visual Impairment and Blindness, 98, 676-678.

Hill, E. W., \& Blasch, B. B. (2010). Concept Development. In R. L. Welsh, \& B. B. Blasch (Ed.), Foundation of Orientation and Mobility (3rd ed.), New York: AFB Press, American Foundation for the Blind.

Holbrook, M. C. (2006). Children with Visual Impairments: A Parents' Guide. Ed. (2nd ed.). Bethesda, MD: Woodbine House.

Jessup, G., Bundy, A. C., Broom, A., \& Hancock, N. (2017). The Social Experiences on High School Students with Visual Impairment. Journal of Visual Impairment \& Blindness, 111, 5-19.

Kail, R. V. (2015). Children and Their Development (7th ed.). Upper Saddle River, NJ: Prentice-Hall.

Lieberman, L. J., Haegele, J. A., Columna, L., \& Conroy, P. (2014). How Students with Visual Impairments Can Learn Components of the Expended Core Curriculum through Physical Education. Journal of Visual Impairment \& Blindness, 108, 239-248.

MacCuspie, P. A. (1996). The Social Acceptance of Children with Disabilities: From Tolerance to Inclusion. Atlantic Provinces Special Education Authority: Halifax Nova Scoytia Canada.

MacCuspie, P. A. (2001). The Social Acceptance and Interaction of Visually Impaired Children in Integrating Setting. In S. Z. Sacks, L. S. Kekelis, \& R. Gaylord-Ross (Eds.), The Development of Social Skills by Blind and Visually Impaired Student: Exploratory Studies and Strategies (pp. 83-102). New York: AFB Press, American Foundation for the Blind.

Malaysian Ministry of Education (2011). The Circular Professional. Putrajaya Malaysia: The Ministry of Education.

Malaysian Ministry of Education (2012). National Education Policy (3rd ed.). Putrajaya: Education Planning Research and Development.

McDevitt, T. M., \& Ormrod, J. E. (2016). Child Development and Education, Student Value (6th ed.). New Jersey: Pearson Education Inc.

Ruijs, N. M., Peetsma, T., \& Van Der Veen, I. (2010). The Presence of Several Students with Special Education Needs in Inclusive Education and the Functioning of Students with Special Educational Needs. Educational Research Review, 62, 1-37. https://www.tandfonline.com/doi/abs/10.1080/00131881.2010.524749

Sacks, S. Z., \& Silberman, R. K. (2000). Social Skills. In A. J. Koenig, \& M. C. Holbrook (Eds.), Foundation of Education: Instructional Strategies for Teaching Children and Youth with Visual Impairment (2nd ed., pp. 616-652). New York, NY: AFB Press American Foundation for the Blind.

Sacks, S. Z., \& Wolffe, K. E. (Ed.) (2006). Teaching Social Skills to Students with Visually Impairment: From Theory to Practice. New York: AFB Press American Foundation for the Blind.

Sacks, S. Z., Kekelis, L. S., \& Gaylord-Ross, R. (2001). The Development of Social Skills by Blind and Visually Impaired Student: Exploratory Studies and Strategies. New York, NY: AFB Press American Foundation for the Blind.

Salleh, N. M., \& Zainal, K. (2010). How and Why the Visually Impaired Students Socially Behave the Way They Do. Procedia Social and Behavioral Sciences, 9, 859-863.

https://doi.org/10.1016/j.sbspro.2010.12.249 
Salleh, N. M., Ali M. M., \& Zainal, K. (2017). Basic Social Behavior Skills among Students with Visual Impairment. Jurnal Pendidikan Malaysia, 43, 41-49.

Santrock, J. W. (2015). Children (13th ed.). New York, NY: McGraw-Hill Companies Inc.

Schunk, D. (2012). Learning Theories: An Educational Perspective (6th ed.). Boston: Pearson Education, Inc/Allyn \& Bacon.

Tuttle, D. W., \& Tuttle, N. R. (2004). Self-Esteem and Adjusting with Blindness: The Process of Responding to Life's Demands (3rd ed.). Springfield: Charles C Thomas Publisher Ltd.

Visagie, L., Loxton, H., Stallard, P., \& Silverman, W. K. (2017). Insights Into the Feelings, Thoughts, and Behaviors of Children with Visual Impairments: A Focus Group Study Prior to Adapting a Cognitive Behavior Therapy-Based Anxiety Intervention. Journal of Visual Impairment \& Blindness, 111, 231-246.

Zainal, K. (2014). Managing Students Discipline in School. Bangi: Universiti Kebangsaan Malaysia Publisher.

Zainal, K., \& Salleh, N. M. (2012). Case Study of Ethnic Behavior among Students in Urban and Rural Schools. The International Journal of Knowledge, Culture \& Change Management, 11, 161-169. 